\title{
Effect of Desiccant Solution Temperature on Regeneration Performance of a Cross-Flow Regenerator
}

\author{
Hye-Won Dong ${ }^{1}$, Hye-Jin Cho ${ }^{1}$, and Jae-Weon Jeong ${ }^{1, *}$ \\ ${ }^{1}$ Department of Architectural Engineering, College of Engineering, 04763 Seoul, Republic of Korea
}

\begin{abstract}
The purpose of this study is to investigate the effect of the inlet solution temperature on the performance of an adiabatic cross-flow regenerator using a lithium chloride $(\mathrm{LiCl})$ aqueous solution, and to propose the optimal inlet solution temperature when operating this type of regenerator. In the experimental tests, the inlet solution temperature range varied from 50 to $90^{\circ} \mathrm{C}$. The tests were carried out at $10^{\circ} \mathrm{C}$ intervals while the other conditions remained constant. The measurement parameters for the test were the inlet air drybulb temperature and humidity ratio, outlet air dry-bulb temperature and humidity ratio, air volume flow, solution density, and inlet and outlet solution temperatures. The regeneration effectiveness and coefficient of performance (COP) were selected to assess the heat and mass transfer performance of the cross-flow regenerator. The most important finding of this research was to determine the optimal solution inlet temperature in the cross-flow regenerator with the $\mathrm{LiCl}$ aqueous solution considering both the regenerator performance and energy consumption. The test results show that the recommended inlet solution temperature is $60^{\circ} \mathrm{C}$, considering both regeneration effectiveness and COP.
\end{abstract}

\section{Introduction}

Liquid desiccant systems have been introduced as nonvapor compression systems in the air conditioning of buildings [1]. These systems have the potential to lower carbon emissions and reduce the negative environmental impact of the conventional air conditioning system. The liquid desiccant system comprises an absorber and a regenerator. Process air is dehumidified with a strong solution in the absorber by the vapor pressure difference between the air and the solution, and the strong solution is diluted. The regenerator is one of the main components in the liquid desiccant system and it is used for the regeneration of a weak solution into a strong solution through the utilization of a heat source. Heat is the main issue for the regenerator because it accounts for the majority of the energy consumed by the liquid desiccant system and therefore influences the performance of the system.

Yin et al. [2] conducted a feasibility study on a crossflow regenerator with hot air using a mathematical model. In the referenced study, a lithium chloride ( $\mathrm{LiCl})$ aqueous solution was selected as the desiccant solution, and the inlet desiccant solution temperature was set to $35^{\circ} \mathrm{C}$. The results indicated that the recommended air temperature should be $65^{\circ} \mathrm{C}$ and that the maximum thermal efficiency was achieved when the air-to-desiccant flow rate ratio was 8. Bassuoni [3] carried out an experiment on a structured packing cross flow desiccant dehumidification system (DDS) using a calcium chloride solution. The experiment was conducted with the solution temperature ranging from $53^{\circ} \mathrm{C}$ to $84^{\circ} \mathrm{C}$ and the results showed that increasing the inlet solution temperature increased the moisture removal rate in the regenerator, while the regeneration effectiveness and the coefficient of performance (COP) of the DDS were decreased.

Parametric studies have showed that the regeneration rate or mass transfer coefficient increases with increasing solution temperature [3-6]. From previous studies, or a principle of regeneration, the regeneration rate is expected to increase with increasing solution temperature. The increase in solution temperature indicates energy consumption; however, the temperature cannot increase indefinitely. The regenerator also varies in terms of the type of desiccant solution, packing material, and air and solution flows, and thus, predicting the regenerator performance involves a complicated process and research is required for specific types of regenerators. However, there has been little research or experimentation on the cross-flow regenerator using $\mathrm{LiCl}$ solution over a comprehensive range of solution temperatures.

Consequently, this research was conducted to verify the effect of the inlet solution temperature on the regeneration performance in an adiabatic cross-flow regenerator with the $\mathrm{LiCl}$ aqueous solution, and to recommend the optimal solution temperature based on experimental tests when operating this type of regenerator. The solution temperature for the experiment was set in the range of $50-90^{\circ} \mathrm{C}$, and the measurements were conducted under summer conditions when the regeneration air was hot and humid. The regeneration effectiveness and COP were chosen as the indexes of performance. The results of this study are expected to be used for determining a

\footnotetext{
* Corresponding author: jiwarc@hanyang.ac.kr
} 
suitable solution temperature range for cross-flow regenerators driven by $\mathrm{LiCl}$ solution.

\section{Experimental setup}

\subsection{System overview}

A cross-flow packed-tower regenerator was selected for the experiment. A diagram of the regenerator is shown in Figure 1. When the intake air passes through the regenerator, the weak desiccant solution flows down and exchanges heat and moisture with the air. The desiccant solution is sprayed over the entire surface of the packing material through nozzles. The $\mathrm{LiCl}$ aqueous solution was chosen as the desiccant solution. Outdoor air was used as the regeneration air in this study. The packing material of the regenerator was a honeycomb media with a length, height, width, and specific surface area of $500 \mathrm{~mm}, 400$ $\mathrm{mm}, 300 \mathrm{~mm}$, and $325 \mathrm{~m}^{2} / \mathrm{m}^{3}$.

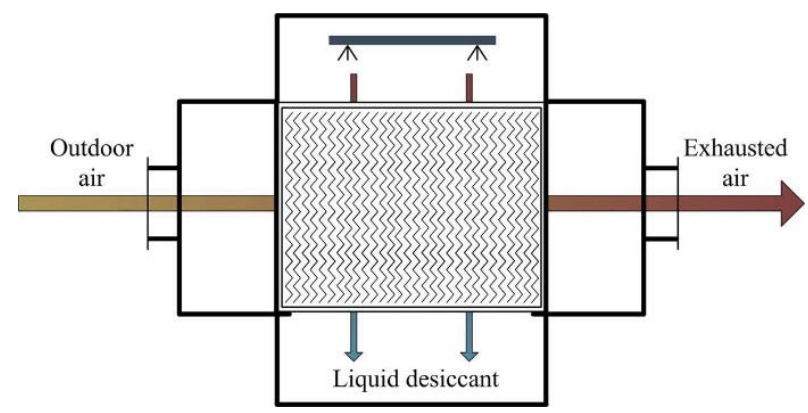

Fig. 1. Diagram of the cross-flow regenerator.

This regenerator system comprises weak and strong solution tanks, a constant flow pump, a constant air volume fan, a control valve, and an electric heating coil. The configuration of the experimental setup is illustrated in Figure 2. Regeneration air was provided from an outdoor air chamber. The chamber was filled by a constant temperature and humidity unit and maintained at target outdoor air conditions. When the outdoor air passed through the regenerator, the weak and heated solutions from the weak solution tank were sprayed. The electric

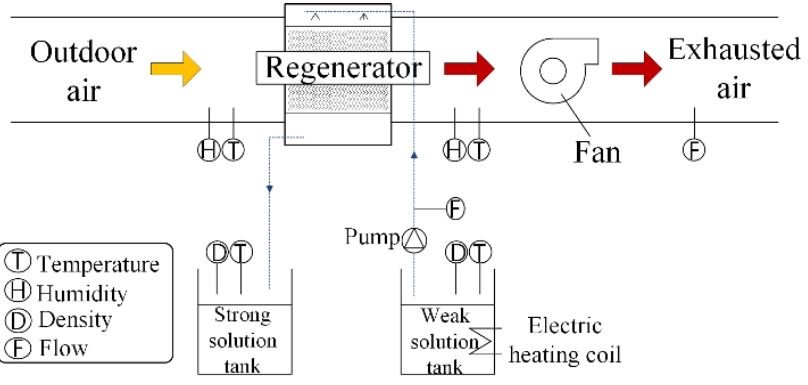

Fig. 2. Experimental setup.

heating in the weak solution tank heated the solution directly. The sprayed solution was collected in the regenerator sump, and the regenerated solution was sent to the strong solution tank. The outlet air was exhausted to the external environment.

The experimental test was carried out to analyze the effect of solution temperature on regenerator performance. The measurement parameters for the test were the inlet air dry-bulb temperature and humidity ratio, outlet air drybulb temperature and humidity ratio, air volume flow, solution density, and inlet and outlet solution temperatures; the measuring points are shown in Figure 2. The inlet and outlet dry-bulb temperatures and humidity ratio were measured by a humidity/temperature probe. The temperature of the desiccant solution was measured by a portable thermometer. The concentration of the desiccant solution was determined by measuring the density of the solution with a density meter. The mass flow rate of the regeneration air was determined by the velocity of the outlet air measured by a vane sensor. Table 1 lists the range and accuracy of each sensor.

The experiment was performed under summer operation conditions because liquid desiccant systems are generally used in hot and humid conditions. The inlet solution temperature ranged from $50-90^{\circ} \mathrm{C}$, and the tests were carried out at $10^{\circ} \mathrm{C}$ intervals while the other conditions remained constant. The outdoor air condition, air mass flow rate, solution mass flow rate, and concentration were set as constant to evaluate the effect of the regeneration solution temperature. Table 2 lists the test parameters and measurement ranges.

Table 1. Sensor characteristics.

\begin{tabular}{|c|c|c|c|}
\hline Parameter & Sensor type & Range & Accuracy \\
\cline { 1 - 1 } Air temperature & NTC (Capacitive humidity & -20 to $55^{\circ} \mathrm{C}$ & $\pm 0.4^{\circ} \mathrm{C}\left(-20\right.$ to $\left.55^{\circ} \mathrm{C}\right)$ \\
\cline { 1 - 3 } & $\begin{array}{c}\text { sensor) } \\
\text { Air humidity }\end{array}$ & $0-100 \% \mathrm{RH}$ & $\begin{array}{c} \pm 1 \% \mathrm{RH}\left(2 \text { to } 98 \% \text { at } 25^{\circ} \mathrm{C}\right) \\
\pm 0.03 \% \mathrm{RH} / \mathrm{K}\end{array}$ \\
\cline { 1 - 3 } Air flow rate & Wheel measuring head $100 \mathrm{~mm}$ & $0.10-15.00 \mathrm{~m} / \mathrm{s}$ & $\pm(0.1 \mathrm{~m} / \mathrm{s}+1.5 \%$ of measurement value $)$ \\
\hline Solution temperature & NTC (portable thermometer) & $-50-250^{\circ} \mathrm{C}$ & $\pm 0.5^{\circ} \mathrm{C}\left(-30.0\right.$ to $\left.99.9^{\circ} \mathrm{C}\right)$ \\
\hline Solution flow rate & Ultrasonic flow meter (TFM 100$)$ & $0-32 \mathrm{~m} / \mathrm{s}$ & $\pm 1.0 \%$ \\
\hline Solution density & Glass hydrometer & $1000-1400 \mathrm{~kg} / \mathrm{m}^{3}$ & $1 \mathrm{~kg} / \mathrm{m}^{3}$ \\
\hline
\end{tabular}


Table 2. Test conditions.

\begin{tabular}{|c|c|c|}
\hline \multicolumn{2}{|c|}{ Parameter } & Value \\
\hline \multirow{2}{*}{ Outdoor air } & Temperature & $31.9 \pm 0.4^{\circ} \mathrm{C}$ \\
\cline { 2 - 3 } & Humidity ratio & $21.0 \pm 1.4 \mathrm{~g} / \mathrm{kg}$ \\
\hline Air mass flow rate & $1.8 \pm 0.0002 \mathrm{~g} / \mathrm{m}^{2} \mathrm{~s}$ \\
\hline Solution mass flow rate & $1.8 \pm 0.0002 \mathrm{~g} / \mathrm{m}^{2} \mathrm{~s}$ \\
\hline Solution concentration & $34.9 \pm 0.12 \%$ \\
\hline
\end{tabular}

The operating duration at each solution temperature was 20 minutes. The values measured by each sensor were stored in a data logger at 10 -sec intervals, which is the minimum measuring rate of the air temperature and humidity sensor.

\subsection{Performance indices}

To recommend a proper solution temperature considering regeneration performance, the regeneration effectiveness $\left(\varepsilon_{r e g}\right)$ and COP were selected as indices for regenerator performance analysis, as shown in Equations 1 and 2.

The regeneration effectiveness can be defined as the ratio of the actual moisture removal rate to the maximum moisture removal rate. In Equation 3, the equilibrium humidity ratio $\left(\omega_{e q}\right)$ is defined using the solution pressure $\left(P_{\text {sol }}\right)$ and atmospheric pressure $\left(P_{a t m}\right)$. In this study, the regeneration COP is defined as the ratio of latent heat removed from the desiccant solution to energy input for solution heating. The latent heat removed can be calculated by using regeneration rate (Equation 4) and latent heat of vaporization $\left(h_{f g}\right)$. The base temperature $\left(T_{\text {base }}\right)$ indicates the room temperature (i.e., $25^{\circ} \mathrm{C}$ ) and target temperature $\left(T_{\text {target }}\right)$ is each solution temperature (i.e., $50-90^{\circ} \mathrm{C}$ ).

$$
\begin{gathered}
\varepsilon_{\text {reg }}=\frac{\left(\omega_{\text {out }}-\omega_{\text {in }}\right)}{\left(\omega_{\text {eq }}-\omega_{\text {in }}\right)} \\
\mathrm{COP}=\frac{\dot{m}_{\text {reg }} \times h_{\text {fg }}}{\dot{m}_{\text {sol }} \times c p_{\text {sol }}\left(T_{\text {target }}-T_{\text {base }}\right)} \\
\omega_{\text {eq }}=0.622 \times \frac{P_{\text {sol }}}{P_{\text {atm }}-P_{\text {sol }}} \\
\dot{m}_{\text {reg }}=\dot{m}_{\text {oa }} \times\left(\omega_{\text {out }}-\omega_{\text {in }}\right)
\end{gathered}
$$

\section{Experimental results}

In this study, an experiment was conducted to determine the optimal inlet solution temperature considering the regeneration performance of a cross-flow regenerator using a $\mathrm{LiCl}$ aqueous solution. The regeneration performance can be expressed by regeneration effectiveness and COP using Equations 1 and 2, respectively.

Figure 3 shows the data of the inlet and outlet air conditions measured at 10 -sec intervals on a psychrometric chart according to the inlet solution temperature ranging from $50-90^{\circ} \mathrm{C}$, before calculating the regeneration effectiveness and COP. The experimental test data were measured per minute under the test conditions listed in Table 2. From Figure 3, it can be seen that the humidity ratio difference steadily increased with the increase in inlet solution temperature. The temperature of outlet air also increased as the effect of the solution temperature compared to that of the inlet air.

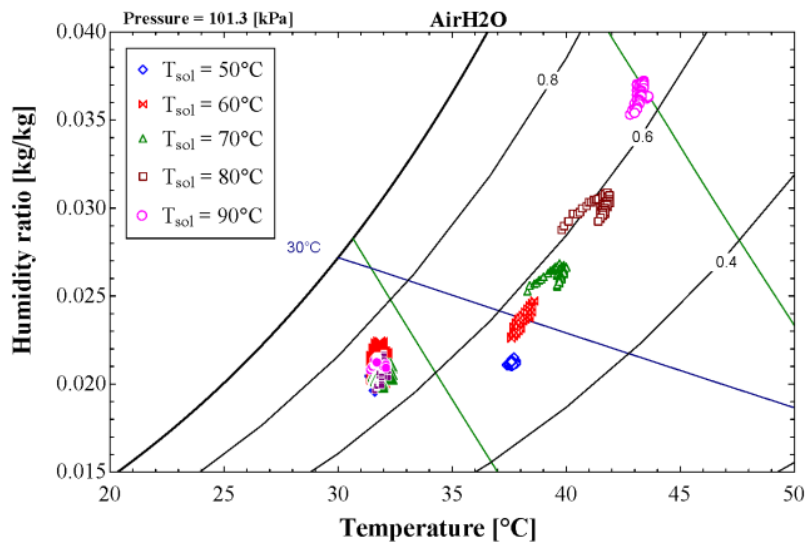

Fig. 3. Experimental data of inlet and outlet air conditions on psychrometric chart.

Based on the measured data, the regenerator performance indices (i.e., the regeneration effectiveness, and COP) were determined at each regeneration temperature of the desiccant solution using Equations 14. Figure 4 shows the measured regeneration effectiveness at various solution temperatures. It is clear from Figure 4 that the regeneration effectiveness decreased with inlet solution temperature. When the room temperature is about $25^{\circ} \mathrm{C}$, the $\mathrm{COP}$ of the regenerator was obtained as shown in Figure 5 although all of the COP were lower than 1 .

Uncertainty analysis was performed for each parameter based on ASHRAE Guidelines 2-2010 [7]. Each parameter was measured every 10 seconds. For the overall uncertainty $\left(U_{X}\right)$ (Equation 5) of regeneration performance indices, the error propagation $\left(B_{X}\right)$ of each uncertainty and the random (precision) component $\left(S_{X}\right)$ representing random uncertainty were calculated using Equations 6 and 7.

$$
\begin{gathered}
\mathrm{U}_{\mathrm{X}}=\sqrt{\mathrm{B}_{\mathrm{X}}^{2}+\left(\mathrm{S}_{\mathrm{X}}\right)^{2}} \\
\mathrm{~B}_{\mathrm{X}}=\left[\sum_{\mathrm{i}=1}^{\mathrm{n}}\left(\frac{\partial \mathrm{X}}{\partial \mathrm{X}_{\mathrm{i}}} \mathrm{b}_{\mathrm{X}_{\mathrm{i}}}\right)^{2}\right]^{1 / 2} \\
\mathrm{~S}_{\mathrm{X}}=2 \mathrm{~S}_{\mathrm{r}} / \sqrt{\mathrm{n}}
\end{gathered}
$$




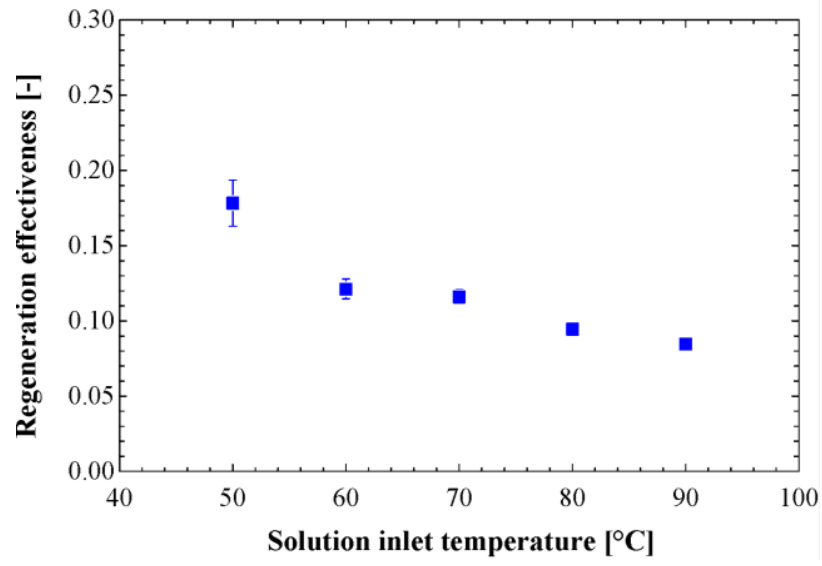

Fig. 4. Effect of solution inlet temperature on regeneration effectiveness.

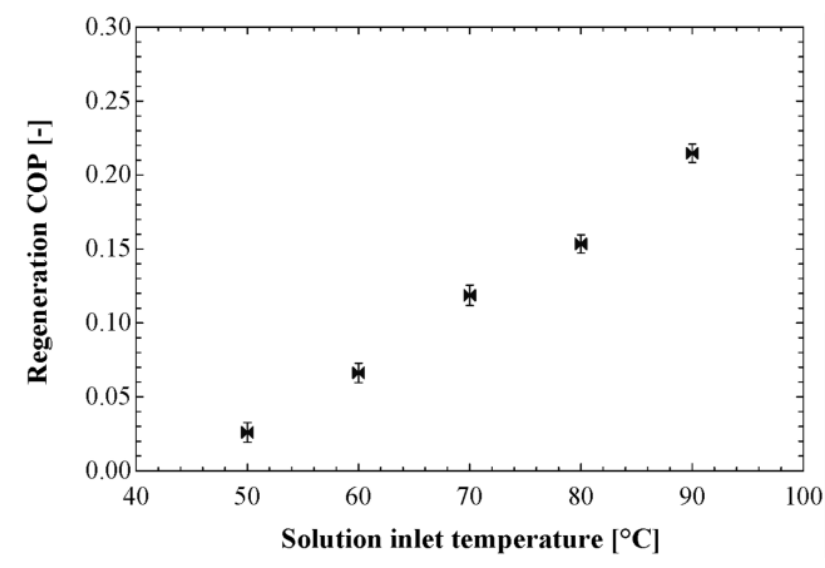

Fig. 5. Effect of solution inlet temperature on regeneration COP.

To determine the appropriate solution temperature, the averaged values of regeneration effectiveness and COP are normalized from 0 to 1 in the solution temperature range from 50 to $90^{\circ} \mathrm{C}$ (Equation 8). Then, the normalized average values of the regeneration effectiveness were connected as a poly-line, and the point where the two curves meet was selected (Figure 6). In this study, the recommended solution temperature is found to be $65^{\circ} \mathrm{C}$ considering both regeneration effectiveness and COP.

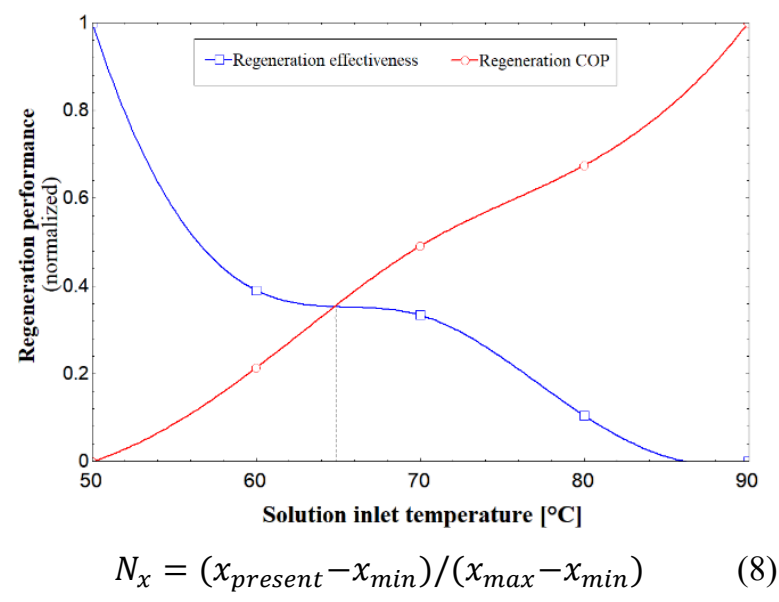

Fig. 6. Optimal solution temperature.

\section{Conclusion}

In this research, an experimental investigation was carried out to evaluate the impact of solution temperature on the regenerator performance of a cross-flow packed-tower regenerator using $\mathrm{LiCl}$ solution as the desiccant solution, and to determine the proper inlet solution temperature for this type of regenerator. The experiment was conducted under summer operation conditions, which are hot and humid. The inlet solution temperature varied from $50^{\circ} \mathrm{C}$ to $90^{\circ} \mathrm{C}$, and the experiment was carried out at $10^{\circ} \mathrm{C}$ intervals, while the other parameters remained constant. Considering both the regeneration and energy performance, the recommended solution temperature determined in this study is $65^{\circ} \mathrm{C}$. Future study should also conduct the experiment in various inlet solution and air conditions to enhance the results.

\section{Acknowledgements}

This work was supported by the Korean Agency for Infrastructure Technology Advancement (KAIA) grants (19CTAP-C141826-02), and by the Korean Institute of Energy Technology Evaluation and Planning (KETEP) (No. 20184010201710).

\section{References}

1. W. Goetzler, R. Zogg, J. Young, C. Johnson, Energy savings potential and RD \& D opportunities for nonvapor compression HVAC technologies, Report prepared by Navigant Consulting Inc. for the U.S Department of Energy (2014).

2. Y. Yin, S. Li, X. Zhang, D. Peng. Feasibility and performance analysis of a desiccant solution regenerator using hot air, Energy Build. 43, 5 (2011).

3. M.M. Bassuoni, An experimental study of structured packing dehumidifier/regenerator operating with liquid desiccant, Energy 36, 5 (2011).

4. N. Fumo, D.Y. Goswami, Study of an aqueous lithium chloride desiccant system: Air dehumidification and desiccant regeneration, Sol. Energy 72, 4(2002).

5. X.H. Liu, Y. Jiang, X.M. Chang, X.Q. Yi, Experimental investigation of the heat and mass transfer between air and liquid desiccant in a crossflow regenerator, Renew. Energy 32 (2007).

6. Y. Yin, X. Zhang, Z. Chen, Experimental study on dehumidifier and regenerator of liquid desiccant cooling air conditioning system, Build. Environ. 42 (2007).

7. ASHRAE Guideline 2-2010, Engineering analysis of experimental data, (2010). 